Running head: PRINCIPLES FOR TRANSDISCIPLINARY DEVELOPMENT

\title{
Principles for Fostering the Transdisciplinary Development of Assistive Technologies
}

Jennifer Boger (Ph.D., P.Eng.) ${ }^{\mathrm{a}, \mathrm{b}}$, Piper Jackson (Ph.D.) ${ }^{\mathrm{c}}$, Maurice Mulvenna (Ph.D.) ${ }^{\mathrm{d}}$, Judith Sixsmith (Ph.D.) ${ }^{\mathrm{e}}$, Andrew Sixsmith (Ph.D.) ${ }^{\mathrm{c}}$, Alex Mihailidis (Ph.D., P.Eng.) ${ }^{\mathrm{a}, \mathrm{b}}$,

Pia Kontos (Ph.D.) ${ }^{a}$, Janice Miller Polgar (Ph.D., OT Reg. (Ont.)) ${ }^{\mathrm{f}}$, Alisa Grigorovich (Ph.D.)a , and Suzanne Martin (Ph.D., Dip. OT) ${ }^{g}$

a Toronto Rehabilitation Institute, University Health Network, Toronto, ON, Canada

${ }^{\mathrm{b}}$ Dept. Occupational Science and Occupational Therapy, University of Toronto, 500 University Ave., Toronto, ON, M5G 2A2, Canada

${ }^{\mathrm{c}}$ Gerontology Research Centre, Simon Fraser University, Vancouver, 2800-515 West Hastings

Street, Vancouver, BC, V6B 5K3, Canada

${ }^{\mathrm{d}}$ School of Computing and Mathematics, Ulster University, Newtownabbey, UK

${ }^{\mathrm{e}}$ University of Northampton, Boughton Green Road, Northampton, NN2 7AL, United Kingdom

${ }^{\mathrm{f}}$ School of Occupational Therapy, Western University, London, ON, Canada

${ }^{g}$ School of Health Sciences, Ulster University, Newtownabbey, UK

Corresponding author: Jennifer Boger, Dept. Occupational Science and Occupational Therapy, University of Toronto, 500 University Ave., $9^{\text {th }}$ floor, Toronto, ON, M5G 1V7, Canada. Email: jen.boger@utoronto.ca

Keywords: Transdisciplinarity, collaboration, principles, innovation, assistive technology.

This is an Accepted Manuscript of an article published by Taylor \& Francis in Disability and Rebabilitation: Assistive Technology, available online: http://www.tandfonline.com/10.3109/17483107.2016.1151953 


\title{
PRINCIPLES FOR TRANSDISCIPLINARY DEVELOPMENT
}

\begin{abstract}
Developing useful and usable assistive technologies often presents complex (or "wicked") challenges that require input from multiple disciplines and sectors. Transdisciplinary collaboration can enable holistic understanding of challenges that may lead to innovative, impactful, and transformative solutions. This paper presents generalised principles that are intended to foster transdisciplinary assistive technology development. The paper introduces the area of assistive technology design before discussing general aspects of transdisciplinary collaboration followed by an overview of relevant concepts, including approaches, methodologies, and frameworks for conducting and evaluating transdisciplinary working and assistive technology design. The principles for transdisciplinary development of assistive technologies are presented and applied post hoc to the $\mathrm{COACH}$ project, an ambient assisted living technology for guiding completion of activities of daily living by older adults with dementia as an illustrative example. Future work includes the refinement and validation of these principles through their application to real-world transdisciplinary assistive technology projects.
\end{abstract}




\section{PRINCIPLES FOR TRANSDISCIPLINARY DEVELOPMENT}

\section{Introduction}

A person's wellbeing (i.e., a person's assessment of his or her physical, emotional, and mental state) is directly and profoundly impacted by his or her ability to achieve the activities required to maintain his or her health and quality of life ${ }^{1}$. For the purposes of this paper, an "assistive technology" constitutes a tool that a person uses to accomplish something that would be difficult or impossible for him or her to do otherwise. With the potential to support a virtually unbounded range of activities, appropriate well-designed assistive technologies can be life-changing by complementing an individual's abilities and enabling him or her to accomplish things they wish to do. However, the development of assistive technologies is inherently complex as their development and adoption takes place within psychological, social, and cultural contexts, while the market for products and services is characterised by fragmentation at international and regional levels, as are regulatory frameworks and service models. Creating useful and usable technologies against the backdrop of ethical, social, psychological, technical, and financial challenges inherent in real-world applications is a challenge that requires many skills, and benefits from the integration of different disciplinary, experiential, and professional perspectives. Such a complex undertaking requires the fusion of expertise from a diversity of backgrounds and sectors, not just to create new ideas, but to imagine new solutions to existing challenges, and create new products and services that are of value to the people who use them.

Information and communication technologies and pervasive computing have an increasingly important role in society, and their influence on the design of assistive technologies is no exception. There are an increasing number of initiatives focused on integrated technologies for supporting wellbeing. For example, the European Ambient Assisted Living Joint Programme ${ }^{2}$ and the Canadian AGE-WELL Network of Centres of Excellence ${ }^{3}$ are major international and national level research and innovation initiatives to explore, develop, and commercialise technology that supports the 


\section{PRINCIPLES FOR TRANSDISCIPLINARY DEVELOPMENT}

independence, health, and wellbeing of seniors. Despite the opportunities for significant social and economic benefits via low-cost products and services, research in this area is challenging ${ }^{4}$; not least is the question of how to mobilise diverse teams of researchers and knowledge users to work together effectively towards the innovation goals. The complex and challenging nature of this research often causes it to go beyond traditional disciplinary boundaries. It is increasingly common to have large project teams from multiple backgrounds (e.g., engineering, information technology, clinical sciences, social science, humanities, business) working with stakeholders from different sectors (e.g., industry, government, service providers) along with significant technology-user input throughout the endeavour $)^{5}$.

This paper presents ideas that may help to address challenges and opportunities of researching assistive technology in a practical way. In particular, the need to work across disciplinary boundaries and sectors using effective practices has become a major topic in its own right, with the concept of transdisciplinarity emerging as a meme in contemporary discourse regarding research, knowledge creation and translation, and market-ready products and services ${ }^{6}$. The goal of this paper is to articulate the principles that we feel are key to transdisciplinary development of assistive technologies. These principles are meant to be adapted into practice as each context requires and are intended to foster united approaches to technology research, development, and deployment. The principles are designed to support the integration of different perspectives, concepts, models, frameworks, and working practices to enable 'out of the box' thinking about a problem space in ways that will lead to deeper understandings and insights that lead to real-world innovations. As such, this paper is not intended to present a definitive methodology or framework, but puts forward an evolving set of heuristic principles that provide orientation and guidance to approaching a research challenge in the area of assistive technology as a transdisciplinary team. 


\section{PRINCIPLES FOR TRANSDISCIPLINARY DEVELOPMENT}

\section{Transdisciplinary collaboration}

The role of different environments, socioeconomic status, desirable outcomes, available technologies, abilities, and preferences of the people who will be using a technology are some of the complex issues that need to be understood and addressed when developing assistive technologies. Collaboration involving experts from multiple relevant areas working together is more likely to result in a more comprehensive understanding of the problem space by enabling access to diverse perspectives and new ways of thinking that would be unknown or not considered by a singlediscipline group. For complicated real-world problems, the likelihood of developing innovative, comprehensive, and appropriate solutions increases in relation to a team's level of collaboration, communication, and cohesion ${ }^{7}$. Past research has attempted to address such complexity using multidisciplinary or interdisciplinary approaches.

Multidisciplinarity, interdisciplinarity, and transdisciplinarity are often used interchangeably, however, there are distinct differences between them ${ }^{8}$. For the purposes of this paper, all three forms are characterised by collaboration between people from any relevant groups, such as team members from different professions, fields, sectors, institutions, communities, levels of expertise, roles (e.g., developers, clients, users, etc.), and disparate geographical locations. Moreover, emergent knowledge can be co-constructed from sources along a continuum, such as scientific to nonscientific and academic to industrial. What does differ is the knowledge that is used and how it is applied. Multi-, inter-, and trans- reflect increasing levels of shared understanding, language, involvement, and knowledge, as shown in Figure 1. Multidisciplinary collaborations involve the input of knowledge from one or more backgrounds to address a shared problem or project; knowledge transfer is essentially unidirectional and is contributed by the collaborators to the project. Interdisciplinary collaborations are more interactional and characterised by bi-directional knowledge transfer, where team members not only contribute knowledge to the project, but gain new 


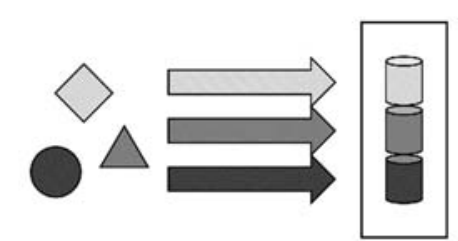

Multidisciplinary

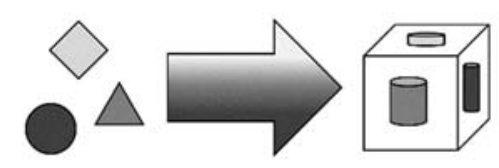

Interdisciplinary

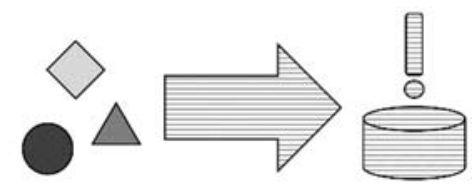

Transdisciplinary

Figure 1. Schematic representation of the differences of how knowledge is used between multidisciplinary, interdisciplinary, and transdisciplinary collaborations.

perspectives through the team's joint efforts. Transdisciplinary collaboration seeks to integrate and amalgamate knowledge from different backgrounds, synthesising, fusing, and extending concepts, methods, and theories by transcending traditional boundaries to systematically create comprehensive, workable, and novel approaches; transdisciplinary working is the cooperative creation of a consensus rather than a search for "fact" or "truth".

Transdisciplinarity can be thought of as an attempt to access "the collective mind" of a team composed of different viewpoints to solve difficult real-world problems, also known as "wicked problems", by bringing about innovative, transformational change ${ }^{9}$. The term wicked problem was first coined in 1973 by Rittel and Webber to describe problems that defy description or categorisation and have "no 'optimal solutions'... in the sense of definitive and objective answers"10. Wicked problems do not have clear a priori solutions, rather collaborators working on a wicked problem continuously gather information, build their understanding, and shape solutions as they work through the problem ${ }^{11}$. The ability to tackle wicked problems is essential in the development of assistive technologies since the experiential knowledge of the target population(s), professional knowledge of service providers and other stakeholders, and socio-scientific as well as humanistic knowledge must come together to address difficult, unstructured problems by re-thinking, re- 


\section{PRINCIPLES FOR TRANSDISCIPLINARY DEVELOPMENT}

working, and co-producing future possibilities. Examples of other domains considered to be wicked problems include climate change, education, armed conflicts, health epidemics, and social injustice.

The amalgamation of ideas from different perspectives enables transdisciplinary teams to leverage collective expertise to create new ways of thinking and problem solving, which support novel and appropriate approaches to solving challenges ${ }^{12}$. Conceptually, transdisciplinarity is an action-oriented approach where research questions emerge through consultation and interaction among several disciplines and sectors to develop socially useful, feasible, practical, effective, and sustainable solutions. In transdisciplinary research, societal real-world needs define the problem area, which in turn dictates which stakeholders need to work together. As such, transdisciplinary research provides an opportunity for transformative solutions in society by executing innovative projects that push through boundaries to impact both established and novel audiences and applications.

Collaborators in transdisciplinary teams are real life stakeholders ${ }^{13}$, ideally using shared innovation strategies. One such strategy is triple-helix engagement, where the three types of stakeholders are industry, government, and academia (also called academic-public-private partnerships) ${ }^{14}$. The triplehelix model and its variants work well within the concept of network economy, facilitating ad hoc or permanent partnerships as required, focused on problem solving as well as commercial exploitation of intellectual property and know-how arising from the partnerships, where appropriate.

The use of models such as the triple-helix explicitly recognises the value of partnerships and the different stakeholders along with their roles in facilitating and supporting innovation. However, there is one other type of stakeholder who has only been occasionally fully involved in innovation processes around service co-creation and development - the technology user. Arguably, the people and services that access and use the technology constitute the ultimate stakeholder group in these processes and indeed the resulting quality of a product or service suffers if representatives from enduser groups are not involved in the design and development processes. User Centered Design 


\section{PRINCIPLES FOR TRANSDISCIPLINARY DEVELOPMENT}

(UCD) is one approach that puts the person at the centre of the design process and has been successfully used in many product designs ${ }^{15}$. The key aim in UCD is to learn what product or service is best suited to meet the needs of the people who will using the technology. It is also used to determine whether the intended benefit arising from the application results in better usability and improves the resulting designed product or service. There is a long tradition of user-oriented, experience-based approaches developed to realise these aims and benefits, including user experience $^{16}$, contextual design ${ }^{17}$, action research ${ }^{18}$, and cooperative (participatory) design ${ }^{19}$. Siew and $\mathrm{Yeo}^{20}$, for example, use participatory action research to augment the development of software for telecenters in rural communities.

In transdisciplinary teams, every team member is considered to be a stakeholder with the goal of participating in the creation of novel knowledge and methods as well as producing innovative outputs (e.g., academic, policy, and industrial applications). Transdisciplinary teamwork involves the close collaboration of many viewpoints, which provides the potential to produce transformational and effective designs (e.g., appropriate incorporation of privacy by design, interfacing, cost, etc.) by leveraging multiple forms of knowledge from a variety of sources ${ }^{21}$. This can include insight regarding how the person or people will likely use the technology, their plausible environment and resources, and the dynamic relationship between factors such as these $\mathrm{e}^{22,23}$. However, while transdisciplinary collaboration can offer the benefits of more holistic teamwork and innovative solutions, creating and managing a transdisciplinary team presents a host of challenges. Moreover, the complexities associated with assembling and managing a transdisciplinary group should be weighed carefully against its necessity because there are many problems that may be solved as a multi-, inter-, or even intra-disciplinary team. In general, the more simple, well-defined, and static (or linear) a problem is, the less it will require many disciplines or sectors to solve it, particularly if there are clear directions to probable solutions. 


\section{PRINCIPLES FOR TRANSDISCIPLINARY DEVELOPMENT}

\section{Relevant concepts}

While transdisciplinary research is a powerful concept in theory, what is needed is guidance regarding how to implement it in the practice of developing assistive technologies. The discussion that follows presents concepts drawn from the literature and examples of the authors' work that provide insights as to how to achieve this goal.

\subsection{Transdisciplinary collaboration}

Hester and Adams ${ }^{24}$ state that as we pass from the machine age (i.e., stand-alone machines) into the systems age (i.e., increasingly connected and inter-communicating devices and systems), problems are becoming more complex and less structured, heralding the need to transition from systematic to systemic ways of thinking and problem solving. Accordingly, they argue, the trend from singular problems toward multiple, inter-related problems requires a shift from striving to achieve a conclusive optimal "end state" to focusing on an increased understanding of the problem space (or mess) in its entirety; philosophically moving from reductionism (i.e., classifying a phenomenon in its simplest terms) to constructivism (i.e., generating knowledge and meaning from interactions between experiences and ideas). Hester and Adams advocate for a move away from rigid systematic and procedural ways of thinking to exploratory and rationalised ones as these are required for a transdisciplinary team to tackle complex problems. They give the analogy of cooking by following a recipe versus knowing the ingredients, but not pre-defining the method and cuisine. As put by Kueffer and colleagues, "the core assumption of transdisciplinary research is that research questions and practices need to be framed according to life-world problems rather than disciplinary

frameworks" 25 . In other words, a transdisciplinary team will develop frameworks and methods to suit the particular real-world problem they are attempting to solve rather than utilising an inappropriate (existing) technique or deforming the problem to fit into existing practices. Similarly, 


\section{PRINCIPLES FOR TRANSDISCIPLINARY DEVELOPMENT}

Klein predicts that the nature of applying transdisciplinarity to diverse and complex problems will defy the creation of unified methodologies, but will foster "utilitarian objectives, although they range from manufacturing new products to new protocols for health care and environmental sustainability"26.

While well-run transdisciplinary initiatives can result in substantive outcomes and could be a helpful predictor for success, there are no established methods for identifying trans-discipline collaboration-readiness factors and mapping them to outcomes ${ }^{27}$. We need to have a way of establishing what works well (and what fails to work) to produce good transdisciplinary outcomes that positively impact real-world problems. The evaluation frameworks that do exist are often intended for a specific research area (e.g., tobacco-use or cancer treatment research). On the whole, evaluation methods need to be established by the research team to document and gauge both intended and unintended progress and outcomes of transdisciplinary work. This is important in relation to developing assistive technologies because of the huge investment in such technologies and their potential to improve people's lives. 'Success' indicators of transdisciplinary working in this field should be based as much on the production of technologies that are useable and improve quality of life as on the production of new knowledge, concepts, and methods.

Various quantitative and qualitative methods can be employed to establish the 'success' of transdisciplinary working, including surveys of team members, progress relative to desirable milestones and outcomes. Mitchell, Cordell, and $\mathrm{Fam}^{28}$ propose a framework where a team identifies how their collaboration will impact or improve three outcome spaces: situation (i.e., the area of inquiry, which could be a product, service, policy, etc.), knowledge (i.e., the overall body of knowledge and/or how knowledge is exchanged), and learning (i.e., collaborators coming away with new perspectives). While this framework provides a good starting point, situation is problematically generic, since it does not recognise fundamental differences; at a minimum, there should be separate 


\section{PRINCIPLES FOR TRANSDISCIPLINARY DEVELOPMENT}

spaces for research and non-research outcomes. Recognising teamwork as an outcome is also crucial, both due to the effort and value in building up a transdisciplinary team, but also due to the ongoing impact of social ties even after a project has ended. Moreover, even within a highly collaborative environment, different backgrounds will emphasise different desirable outcomes. For example, funders typically want to see evidence of a return on investment, academics are interested in advancing the state of knowledge, and knowledge users want to make informed decisions regarding areas such as resource management, potential industrial impact, and policy implementation $^{29}$. Regardless of the process selected, measures of transdisciplinary success should be sensitive to the requirements of all stakeholders in the group and should be cross-validated to help ensure the perceived evaluation is accurate.

In addition to evaluating project progress and successful outcomes, it is valuable to be able to continually establish the effectiveness of a transdisciplinary team itself. Schauppenlehner-Kloyber and Penker ${ }^{30}$ advocate the application of the concept of Theme-Centred-Interaction to consider and support the requirements of individuals ("I"), interaction and relationships between group members ("we"), the problem the group is focusing on ("it"), and the context where the collaboration takes place ("globe") at all stages of group processes. In her literature review, Klein ${ }^{31}$ identified seven principles that can be used to evaluate the workings of a transdisciplinary team: 1) variability of goals; 2) variability of criteria and indicators; 3) leveraging of integration; 4) interaction of social and cognitive factors in collaboration; 5) management, leadership, and coaching; 6) iteration in a comprehensive and transparent system; and 7) effectiveness and impact. Klein concluded that methods for evaluating cross-disciplinary research in general is an emerging topic, and efforts to establish appropriate indicators can be impeded when rigid discipline, peer, or measurement standards are imposed, stating that a single or uniform evaluation method would be "antithetical to the multidimensionality and context-specific nature of interdisciplinary and transdisciplinary work" ${ }^{31}$. 


\section{PRINCIPLES FOR TRANSDISCIPLINARY DEVELOPMENT}

Rather, transdisciplinary projects should investigate and adopt or create evaluative methods that complement their specific needs.

\subsection{Development and evaluation of assistive technology}

A key challenge to creating and evaluating technologies in any domain is capturing the requirements, needs, preferences, and abilities of the intended people who will use the technology, translating this information into design requirements, then creating a complementary solution. This requires a great deal of care to ensure information retains its connotation while being interpreted and used by team members from different backgrounds and for different purposes. Knowledge domains required in relation to assistive technology projects can include: understanding of people in health and social care; understanding of living-in-place and intersections with community participation; medical, technological, and ergonomic considerations; understanding of the activities a person wants to do and the context in which those activities will be done; and knowledge translation, including commercialisation and service delivery. Frameworks or models from different perspectives — which guide the transdisciplinary team to identify and adopt relevant strategies to identify, coalesce, and create appropriate information—are described here to highlight the challenge and complexity of designing and evaluating assistive technology that meets the needs of intended users.

Designing and understanding the impact of technologies have become established as broad and intricate areas of study. Consequently, many approaches, models, and frameworks have been developed to describe different aspects of people's relationships with technology. For example, the field of human-computer interaction has offered approaches such as situated action and embodied interaction in an attempt to provide ways of gaining a comprehensive understanding of the problem space. Situated action proposes that an intelligent (animal or computer-based) agent's actions are 


\section{PRINCIPLES FOR TRANSDISCIPLINARY DEVELOPMENT}

inseparable from the agent's current perception of context; namely, while an agent may plan how to achieve a task, their actions reflect their real-time perception of the world ${ }^{32}$. Similarly, embodied interaction stipulates that context is a dynamic entity that continually redefines itself relative to related activities ${ }^{33}$. Moreover, embodied interaction holds that how and why a person engages with another entity or thing determines what elements of the interaction are considered to be meaningful to them. In the field of occupational science, transactionalism has been offered as a way for occupational therapists and scientists to gain insight into ways of doing and being in various contexts. Couched in the context of occupational science, transactionalism proposes that a person has ongoing, dynamic, and evolving interrelationships with their environment (e.g., people, places, things, situations, and cultures) and that a person continually selects actions which shape their environment while their environment reciprocally shapes him or her ${ }^{34}$. A person's inherent preference is for actions that are most likely to result in maintaining or restoring their sense of functional coordination, which itself is dynamic and responsive to the person-environment relationship.

These perspectives highlight the dynamic nature of use of assistive technology, and the complexity associated with device design and evaluation. They are congruent with transdisciplinary concepts and useful as an approach for a development team to gain a high-level view of the intertwined, complex, and dynamic relationship among a person, his or her activities, and environment. They guide the understanding of how a technology influences this relationship. Dynamic and transactional philosophies can help guide the team to create technologies that complement the needs, preferences, abilities, and resources of the people most likely to use the technology. Moreover, as philosophies are epistemological in nature, they are usually accessible across disciplines and sectors. 


\section{PRINCIPLES FOR TRANSDISCIPLINARY DEVELOPMENT}

At a more detail-oriented level, models and frameworks have been put forward to assist in the design and selection of appropriate assistive technologies. Cook and Polgar's ${ }^{22}$ Human, Activity, Assistive Technology (HAAT) Model describes a person performing an activity, using assistive technology, within a context. The model has applications for product development, service delivery and outcome evaluation. The model is composed of four elements: 1) activity, which includes selfcare, productivity, and leisure, as well as notions such as frequency of engagement, 2) the person, including physical, cognitive, emotional, and sensory performance, as well as degree of expertise, roles, and meaning, 3) context, which includes physical, social, cultural and institutional elements, and 4) technology, which includes the human/technology interface, processor, environmental interface and activity output. The model is founded on principles that are person-centred, ethical, evidenceinformed, sustainable, incorporate social justice, and focus on functional outcomes. Cook and Polgar suggested that application of the model first considers the activity or functional outcome, and then the characteristics of the intended person who will use the technology and the context(s) in which the activity is conducted. The assistive technology is considered last in order to keep the focus on the human performing an activity in context, rather than on the assistive technology, thus encouraging the identification of interventions that complement the particular person and their context. Scherer, Jutai, Fuhrer, Demers, and Deruyter" ${ }^{35}$ presented a "framework for modelling the selection of assistive technology devices (ATDs)" that identifies key factors that influence the outcomes of assistive technology use. These factors include both the personal (e.g., resources, knowledge, expectations, preferences) and environmental (e.g., cultural and financial priorities, legislation, social). Elements of the function of the device are also included, such as effectiveness and device satisfaction. This framework highlights the complexity of conceptualising and evaluating the outcome of AT use as well as the multiple perspectives necessary to understand and interpret these outcomes. 


\section{PRINCIPLES FOR TRANSDISCIPLINARY DEVELOPMENT}

Understanding the influence of product and environmental design on the ability to engage in activity is another consideration that can affect technology. Universal design is defined as the "design of products and environments that can be used and experienced by people of all ages and abilities, to the greatest extent possible, without adaptation" ${ }^{\prime 36}$, and is associated with seven Principles of Universal Design that indicate which critical factors (such as flexibility, simplicity, and tolerance for error) can increase device usability in terms of diverse levels of ability. In addition to this, inclusive design considers how social and economic differences affect usability, and encourages the involvement of users in the design process ${ }^{37}$. These approaches raise awareness of how design enables or constrains use and function, and promote flexible product design; namely, creating designs that complement as many people in the target population as possible.

Creating a comprehensive product requires holistic vision. Technology developers should be cognisant of the entire innovation pathway from problem identification to an implemented, realworld solution, even if they are focusing on a particular stage of development. Keeping in mind 'the bigger picture' can help transfer knowledge from the research stage through development and onward to socio-economic impact. The Need to Knowledge model put forward by Flagg, Lane, and Lockett $^{38}$ is a market-oriented approach that outlines the stages and outputs for the discoveryinvention-innovation pathway. The intention of the model is to lay out the activities and milestones associated with innovation generation, thereby enabling teams working at any stage to plan for future stages.

Technology Readiness Levels (TRLs) are a "systematic metric/measurement system that supports assessments of the maturity of a particular technology and the consistent comparison of maturity between different types of technology" ${ }^{\prime 39}$. These levels were developed by NASA to help them understand the maturity levels of emerging technologies, from basic principles, through validation in the lab, all the way to system use in an operational environment ${ }^{40}$. TRLs have been 


\section{PRINCIPLES FOR TRANSDISCIPLINARY DEVELOPMENT}

adopted by many public sector organisations around the world including the US Department of Defense, US Department of Energy, the European Space Agency and the European Commission ${ }^{40}$. TRLs are an example of a way for a team from different backgrounds and sectors to plan a project's path and to agree upon, set, and assess milestones related to a technology's levels of functional maturity.

\section{Principles of transdisciplinary development of assistive technologies}

The above discussion is intended to give the reader some idea of what transdisciplinary collaborations entail and become familiar with some methods that could help transdisciplinary teams to analyse, describe, and evaluate their project. The set of principles we propose below are meant to provide generalised guidance that facilitates the implementation of transdisciplinary collaboration in the context of developing assistive technologies. They are intended to help transdisciplinary groups to address the concerns of how to work together, i.e., the mode of collaboration. As such, they:

1. are flexible to suit different design contexts,

2. are applicable across disciplines and sectors, and

3. provide operational guidance toward technology development by a transdisciplinary team.

While less abstract than a philosophy, they are more flexible than a model, framework, or exemplary best practices, and can be adopted and tailored to suit the needs of a project and its team members. They provide complementarity to established practices that may allow for better identification of useful techniques and tools, negotiation of different perspectives, and ensuring that all necessary different perspectives are integrated. These principles do not dictate what methods or techniques should be employed to achieve project, teamwork, knowledge transfer, or other goals; namely, they are intended to highlight aspects that need to be continuously addressed for 'successful' 


\section{PRINCIPLES FOR TRANSDISCIPLINARY DEVELOPMENT}

transdisciplinary teamwork to take place, both in terms of process and outcome. The particulars regarding how this is accomplished will be contingent on each project and will need to be established, monitored, and managed by the project's team. The principles are presented as practical considerations to aid the adoption of transdisciplinary working and provide guidance for overcoming challenges associated with this kind of work; for the consideration of existing transdisciplinary research efforts, the evaluation frameworks presented in ${ }^{41}$ may be more appropriate.

To aid comprehension, the principles have been arranged into four domains: complexity and holism, relationships, communication, and transformation. These domains represent the associated principles' primary focus, however, there is much overlap between principles and domains.

\subsection{COMPLEXITY and HOLISM}

With respect to complexity and holism, a transdisciplinary team should strive to:

Address wicked, needs-driven, real world problems through innovation, both creative as well as disruptive. Transdisciplinary collaboration is well suited to undefined problems that do not have apparent solutions. Regardless of the eventual output (e.g., product, best practice, policy), the motivation for its development should be grounded in a need identified through a participatory process and be applicable to real-world implementation.

Have an attentiveness and appreciation of complexity. Apply approaches that capture and address the complexity and pressing nature of real-world problems; a holistic rather than a reductionist approach. This entails both an emphasis on learning about the idiosyncrasies of the problem, as well as being practical about solutions might have an impact and how to produce them. 


\section{PRINCIPLES FOR TRANSDISCIPLINARY DEVELOPMENT}

Cross ideational borders by sharing ideas as well as creating new ones as team members learn from each other. Leverage each other's knowledge to understand, explore, and develop solutions to a problem in a more holistic way.

Have a common understanding of problems by not only accessing the knowledge and opinions of team members, but by accessing multiple viewpoints from relevant external people or groups who can inform solution development and implementation.

Share goal creation. Define and set the project's goals and outcomes in a participatory manner so that significant priorities for all team members are being met. Collectively plan how to achieve goals, identify and acknowledge the achievement of significant milestones, and collectively revise unmet goals. Pursue planning as a flexible, open, and ongoing process in order to encourage and maintain the involvement of all stakeholders ${ }^{42}$.

\subsection{RELATIONSHIPS}

With respect to relationships, a transdisciplinary team should strive to:

Engage in ongoing inter-sectoral and technology-user involvement. Continuously cocreate knowledge through meaningful participation and interaction with different stakeholder groups. This should include relevant academic, industrial, government, and other sectors as well as informants from representative end-users (e.g., people with disabilities, caregivers, service providers, etc.) at every stage of the project.

Challenge accepted ways of researching and working to promote a sense of equality among collaborators (as opposed to an existing academic and professional hierarchies, which maintain the status quo regarding what is important and whose ideas predominate); be willing to let go of one's biases or established ways of doing things. 


\section{PRINCIPLES FOR TRANSDISCIPLINARY DEVELOPMENT}

Foster trust and respect. Cultivate open-mindedness, patience, goodwill, and cooperation. These are critical for enabling the mutual support necessary for achieving both project and individual goals. Appreciate the wide diversity found in collaborators; typical markers of status are generally less useful in a transdisciplinary context, where they may be more likely to cause oversight than provide guidance.

Maintain high-levels of tolerance, commitment, and resilience, which enable team members to maintain open relationships and persevere through differences of opinion, conflicting approaches, and disagreements.

\subsection{COMMUNICATION}

With respect to communication, a transdisciplinary team should strive to:

Engage in clear, transparent, ongoing communication, as this is essential to enabling core team functions, including project management, fostering relationships, growing trust, and ensuring messages and ideas are being received and interpreted accurately. Good communication is key to bridging disciplinary and sectoral gaps to produce knowledge in a form that is usable by others.

Agree on a shared vocabulary. The same word may have very different meanings depending on a person's background (disciplinary, sectoral, cultural, etc.). Explicitly developing a shared, agreed upon vocabulary as a team will help to avoid misunderstandings and promote clarity.

Use frameworks and methodologies as appropriate. A benefit to working in a group with multiple backgrounds is inherent knowledge of a gamut of methodologies and frameworks that can be employed to elicit and structure information. This means that the selection of frameworks and methodologies is a complicated issue: not only it is challenging to determine which are most appropriate when facing many options, it can also require a significant amount of team member 
training. Thus, expected benefits must be weighed carefully against the cost of adoption, and considerations of common practice left aside.

\subsection{TRANSFORMATION}

With respect to transformation, a transdisciplinary team should strive to:

Critically identify and challenge assumptions, at both a personal and project level. The ability to critically examine and accept others' perceptions of biases and pre-conceived notions can help to appreciate differing points of view and build a shared understanding. Make explicit your own assumptions and be open to when people point them out. This involves reflexively examining your personal and discipline-derived assumptions with respect to established fields, practices, policies, and beliefs.

Achieve outcomes that have a transformative, real-world impact, such as new products, services, policies, and/or practices that fundamentally changes the way people do things; outcomes establish "better" alternatives that are implementable in real-world contexts.

Push beyond common ground to establish a deeper level of understanding. Part of the process of arriving at solutions to the targeted problems is to develop new knowledge and ways of doing things. The team should transcend established conceptual ideas to create novel and shared methodologies, processes, and frameworks. This can include foundational knowledge for new areas of application, as well as transferable techniques generated as a result of collaboration.

Practice accessible knowledge translation, including knowledge mobilisation and commercialization; namely, people within and external to the team should be able to readily access knowledge that is created through the collaborative efforts. This can take the form of information as well as products. 


\section{PRINCIPLES FOR TRANSDISCIPLINARY DEVELOPMENT}

Work in an iterative fashion to allow for transformational processes. The research design should be recursive, or involve an iterative process whereby team members can cycle back and forth between the different phases of the research as they adapt to changes over time due to reflexive engagement, critical reflection, feedback from stakeholders, as well as insight and new questions raised by intermediate results.

Maximise impact. Transdisciplinary collaboration naturally lends itself to overcoming crosssector barriers, enabling knowledge translation in many directions. From project conceptualisation through to completion, the team should aim to deliver knowledge in ways that ultimately maximise the efficacy of technologies that support wellbeing. This includes bringing a technology to market as well as passing new knowledge back into the team members' original fields.

\section{Example of transdisciplinary work: The $\mathrm{COACH}$ project}

We turn now to the $\mathrm{COACH}$ project as an example of transdisciplinary working. $\mathrm{COACH}$ is an ambient assisted living technology that employs artificial intelligence to autonomously provide audio-visual prompts to older adults with dementia to guide them through steps required to complete activities of daily living, depicted in Figure 2. COACH employs computer vision to capture what is happening in the task it is guiding and uses artificial intelligence to determine if the person requires assistance and, if so, the structure of the assistance that is given. A noteworthy aspect of $\mathrm{COACH}$ is its ability to autonomously learn about the person using it to adjust prompting to suit the preferences and stage of dementia of the person using it by matching the timing and structure of prompt to the person's abilities and preferences. COACH is a zero-effort technology ${ }^{43}$, meaning it functions without any intentional (explicit) input from the person with dementia or their caregiver, thereby promoting a person with dementia's independence while simultaneously decreasing caregiver burden. Collaborators on the $\mathrm{COACH}$ project included people with dementia, formal and familial caregivers, engineers, computer scientists, occupational therapists, speech language 
pathologists, human factors experts, and professional actors. More details regarding COACH's development can be found in ${ }^{44-48}$.

Just as the principles presented above are not exclusive to any domain, each example presented in Table 1 is not a solely representation of the principle it illustrates; rather, while the aspects discussed may be primarily categorised by a principle, most are influenced by more than one.

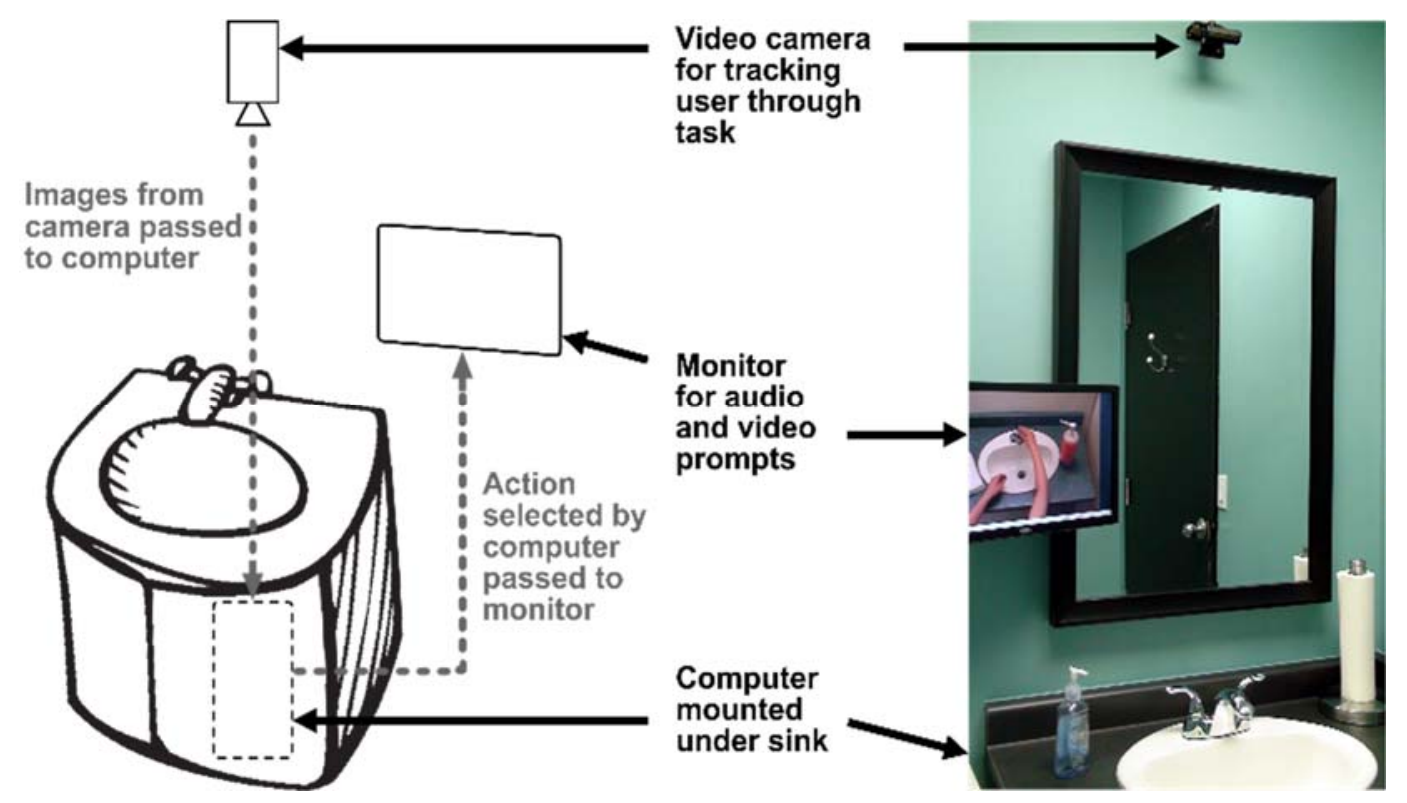

Figure 2. Schematic of the COACH prompting system set up to assist with the activity of hand washing (reproduced from (Boger, 2014)). 
Table 1. Using the $\mathrm{COACH}$ project to illustrate the application of the principles of transdisciplinary development.

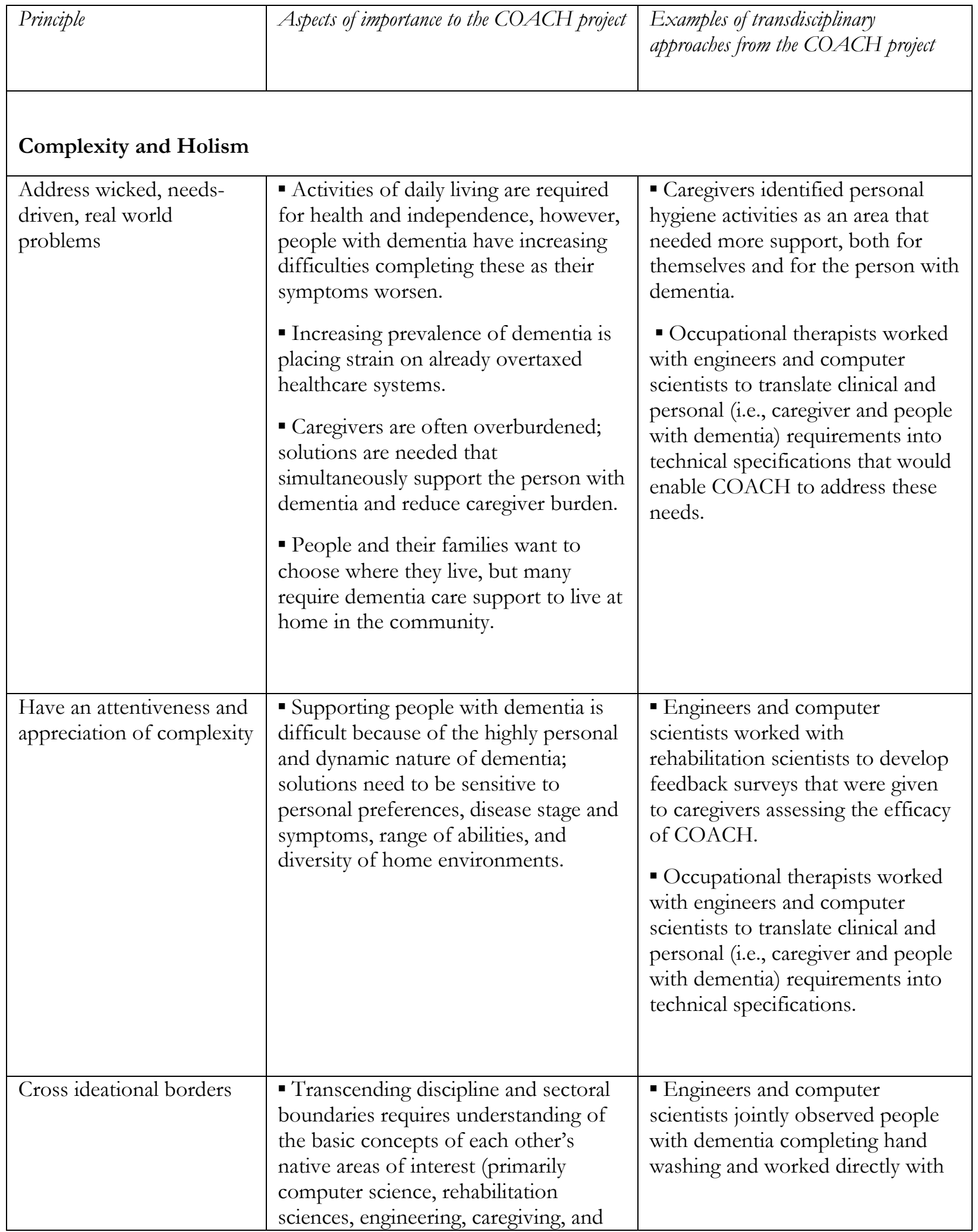


PRINCIPLES FOR TRANSDISCIPLINARY DEVELOPMENT

\begin{tabular}{|c|c|c|}
\hline Principle & Aspects of importance to the $C O A C H$ project & $\begin{array}{l}\text { Examples of transdisciplinary } \\
\text { approaches from the } C O A C H \text { project }\end{array}$ \\
\hline & $\begin{array}{l}\text { people living with / supporting } \\
\text { dementia) as well as a genuine } \\
\text { appreciation for their significance. } \\
\text { - Mutual efforts for a shared level of } \\
\text { comprehension enabled team members } \\
\text { to unite and create novel ways of } \\
\text { moving forward to understand and } \\
\text { address the "bigger picture". }\end{array}$ & $\begin{array}{l}\text { (both family and professional) } \\
\text { caregivers. } \\
\text { - "Technical" experts developed a } \\
\text { first-hand understanding of the } \\
\text { problem (at a cognitive as well as } \\
\text { compassionate level), which fosters } \\
\text { a better sense of solutions that } \\
\text { could be appropriate. } \\
\text { - Healthcare professionals gained } \\
\text { knowledge and appreciation for } \\
\text { technical design requirements, the } \\
\text { design process, and the capacity of } \\
\text { technology. }\end{array}$ \\
\hline $\begin{array}{l}\text { Have a common } \\
\text { understanding of } \\
\text { problems }\end{array}$ & $\begin{array}{l}\text { - Research challenges related to the } \\
\text { technology (i.e., the particular } \\
\text { environment-person-context factors } \\
\text { relevant to the development of a } \\
\text { technology for guiding people with } \\
\text { dementia through activities). } \\
\text { - Research challenges related to each } \\
\text { other's native disciplines and sectors. }\end{array}$ & $\begin{array}{l}\text { - Investigated and gathered } \\
\text { required information as a team } \\
\text { (e.g., asking caregivers what } \\
\text { technology interface they felt } \\
\text { would work best for themselves } \\
\text { and for people with dementia). } \\
\text { Three advantages to this approach } \\
\text { were: 1) provided common-ground } \\
\text { to start thinking about the problem } \\
\text { space; } 2 \text { ) enabled members from } \\
\text { different disciplines/experiences to } \\
\text { elicit different types of information } \\
\text { at the same time; } 3 \text { ) fostered } \\
\text { collaboration and communication } \\
\text { in a natural way; and } 4 \text { ) gave team } \\
\text { members an opportunity to view } \\
\text { first-hand the skill-sets of other } \\
\text { team members. }\end{array}$ \\
\hline Create shared goals & $\begin{array}{l}\text { - COACH's primary goal has been to } \\
\text { create a technology that is useful to, } \\
\text { and is usable by people with dementia } \\
\text { and their caregivers, and is functional } \\
\text { in real-world environments. }\end{array}$ & $\begin{array}{l}\text { - Having a clear primary goal } \\
\text { allowed team members with } \\
\text { different backgrounds and } \\
\text { priorities to align goals and work } \\
\text { together to set and achieve } \\
\text { milestones. } \\
\text { - Testing and evaluating } \\
\text { prototypes with caregivers and } \\
\text { people with dementia embodied a } \\
\text { challenge that required and } \\
\text { encouraged greater levels of } \\
\text { collaboration across disciplines and } \\
\text { experiences. }\end{array}$ \\
\hline
\end{tabular}


PRINCIPLES FOR TRANSDISCIPLINARY DEVELOPMENT

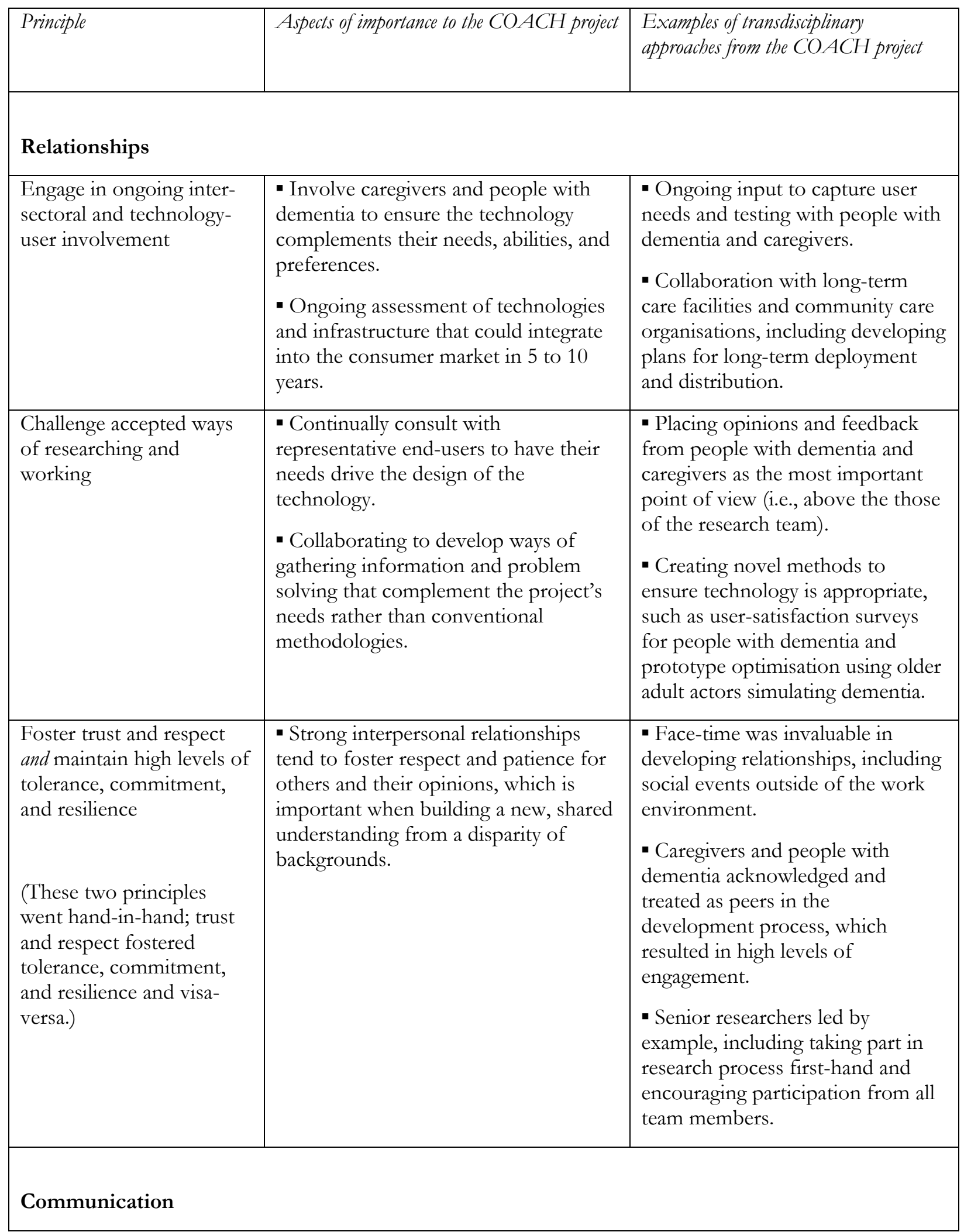


PRINCIPLES FOR TRANSDISCIPLINARY DEVELOPMENT

\begin{tabular}{|c|c|c|}
\hline Principle & Aspects of importance to the $C O A C H$ project & $\begin{array}{l}\text { Examples of transdisciplinary } \\
\text { approaches from the } C O A C H \text { project }\end{array}$ \\
\hline $\begin{array}{l}\text { Engage in clear, } \\
\text { transparent, ongoing } \\
\text { communication }\end{array}$ & $\begin{array}{l}\text { - Supporting good communication } \\
\text { requires continuous efforts that reflect } \\
\text { the needs of the project and its } \\
\text { personnel, which often change over } \\
\text { time. }\end{array}$ & $\begin{array}{l}\text { - In addition to emails, meetings, } \\
\text { and other commonly used } \\
\text { communication strategies, helpful } \\
\text { strategies include open-door policy } \\
\text { (i.e., team members are welcome } \\
\text { to approach each other formally or } \\
\text { informally whenever they feel they } \\
\text { need to) and less conventional } \\
\text { communication technologies, such } \\
\text { as wikis and online repositories to } \\
\text { dynamically share information } \\
\text { through one central location. }\end{array}$ \\
\hline $\begin{array}{l}\text { Agree on a shared } \\
\text { vocabulary }\end{array}$ & $\begin{array}{l}\text { - Developing a shared vocabulary is an } \\
\text { ongoing process, both in terms of } \\
\text { agreeing upon shared terminologies } \\
\text { and educating new team members on } \\
\text { the meanings of agreed-upon } \\
\text { vocabulary. }\end{array}$ & $\begin{array}{l}\text { - When a healthcare practitioner } \\
\text { uses the term "client", s/he is } \\
\text { referring to a person receiving } \\
\text { healthcare services whereas a } \\
\text { computer scientist uses it to refer } \\
\text { to a computer accessing } \\
\text { information from a server. } \\
\text { Similarly, team members educated } \\
\text { each other on current and } \\
\text { acceptable terminologies, for } \\
\text { example, the use of the term } \\
\text { "person with dementia" rather } \\
\text { than "patient". } \\
\text { - The team found it helpful to } \\
\text { collectively agree upon a single } \\
\text { definition for terms that could } \\
\text { cause confusion and, in some } \\
\text { cases, create new terms and } \\
\text { phrases that are mutually } \\
\text { acceptable }\end{array}$ \\
\hline $\begin{array}{l}\text { Use frameworks and } \\
\text { models as appropriate }\end{array}$ & $\begin{array}{l}\text { - Evaluation of prototypes in real- } \\
\text { world environments with } \\
\text { representative users of the technology. } \\
\text { - Compare and contrast efficacy } \\
\text { between different COACH prototypes. }\end{array}$ & $\begin{array}{l}\text { - A new measure based on signal } \\
\text { detection theory was created to } \\
\text { estimate technical efficacy, as there } \\
\text { was no existing standard for } \\
\text { computerised assistive technology } \\
\text { for activity guidance. } \\
\text { - Both technical and clinical } \\
\text { efficacy were evaluated, as it is } \\
\text { important to know if COACH } \\
\text { provides appropriate guidance } \\
\text { relative to clinical best practices } \\
\text { (rather than the device's }\end{array}$ \\
\hline
\end{tabular}


PRINCIPLES FOR TRANSDISCIPLINARY DEVELOPMENT

\begin{tabular}{|l|l|l|}
\hline Principle & Aspects of importance to the $C O A C H$ project & $\begin{array}{l}\text { Examples of transdisciplinary } \\
\text { approaches from the COACH project }\end{array}$ \\
\hline & & $\begin{array}{l}\text { interpretation of the environment, } \\
\text { person, and context). } \\
\text { - Clinical and technical team } \\
\text { members worked together to } \\
\text { investigate how technical and } \\
\text { clinical performance were related } \\
\text { and how they might be improved. }\end{array}$
\end{tabular}

\section{Transformation}

Critically identify and challenge assumptions, at both a personal and project level
- COACH has tackled several assumptions; the three assumptions we have encountered the most are: 1) people will not accept computer vision in their homes, 2) caregivers will resist or resent the use of computerised activity assistance, and 3) people with dementia will become confused or agitated by an "invisible person talking to them".

- Working closely from rehabilitation science, computer science, and engineering backgrounds resulted in many differences of opinion, particularly in the "correct way to do things".
- COACH's development team conducted research to specifically investigate assumptions (e.g., ${ }^{47-50}$ ). Both targeted and incidental evidence gathered over the course of COACH's development enabled the team to address or disprove such assumptions.

- Critically examining assumptions resulted in the team gaining new knowledge regarding technology interfacing and prompting techniques that were applicable to the general field ambient prompting technologies for dementia, as well as COACH.

- A conscience team effort to constructively and critically rethink project-based and personal assumptions can create tension, however, we found the ultimate outcome to usually be a progressive and often innovative shift in perspective and thinking. Trust and good communication have been key to supporting these efforts.

- In pilot trials with people who have dementia, $\mathrm{COACH}$ has been shown to generally increase people's ability to complete hand washing without assistance from a human caregiver, including independent hand washing by some individuals who were 
PRINCIPLES FOR TRANSDISCIPLINARY DEVELOPMENT

\begin{tabular}{|c|c|c|}
\hline Principle & Aspects of importance to the $C O A C H$ project & $\begin{array}{l}\text { Examples of transdisciplinary } \\
\text { approaches from the } C O A C H \text { project }\end{array}$ \\
\hline & $\begin{array}{l}\text { enough for unsupervised deployment } \\
\text { in the community. }\end{array}$ & $\begin{array}{l}\text { previously dependent on a } \\
\text { caregiver for guidance. } \\
\text { - COACH has been cited as a } \\
\text { state-of-the-art neurorehabilitation } \\
\text { intervention in Bieńkiewicz et } \\
\text { al.'s51 paper on apraxia's impact on } \\
\text { activities of daily living and Hoey } \\
\text { et al. } .^{52} \text { winning the best paper } \\
\text { award at the } 5^{\text {th }} \text { International } \\
\text { Conference on Computer Vision } \\
\text { Systems Conference (ICVS). } \\
\text { - The COACH project has } \\
\text { received award-worth recognition, } \\
\text { including Advanced Imaging's } \\
\text { 2008 Imaging Solutions of the } \\
\text { Year Award and } 2007 \text { Finalist in } \\
\text { Celebrating Innovations in } \\
\text { Healthcare Expo, Ontario Ministry } \\
\text { of Health and Long-term Care. }\end{array}$ \\
\hline $\begin{array}{l}\text { Push beyond common } \\
\text { ground to establish a } \\
\text { deeper level of } \\
\text { understanding }\end{array}$ & $\begin{array}{l}\text { - The application of artificial } \\
\text { intelligence to create ambient } \\
\text { prompting for dementia is a multi- } \\
\text { faceted and difficult problem. } \\
\text { - The development of COACH } \\
\text { included systematically investigating } \\
\text { previously unknown areas of research } \\
\text { to obtain the understanding needed to } \\
\text { create a useful and usable device. }\end{array}$ & $\begin{array}{l}\text { - Areas that have been investigated } \\
\text { as a transdisciplinary team include: } \\
\text { studying communication and } \\
\text { prompting strategies used by } \\
\text { formal caregivers to people with } \\
\text { dementia } 53 \text {; the usability of } \\
\text { different types of water faucets by } \\
\text { people with dementia }{ }^{54} \text {; baby- } \\
\text { boomer and older adults' } \\
\text { perceptions regarding the } \\
\text { acceptability of different types of } \\
\text { sensors in different areas of the } \\
\text { home }{ }^{50} \text {; and the use of actors } \\
\text { simulating dementia to optimise } \\
\text { pre-trial prototypes }\end{array}$ \\
\hline $\begin{array}{l}\text { Practice accessible } \\
\text { knowledge translation }\end{array}$ & $\begin{array}{l}\text { - Different disciplines and } \\
\text { dissemination opportunities are } \\
\text { interested in details and points of view } \\
\text { that reflect their background. } \\
\text { - COACH has been disseminated } \\
\text { through several peer-reviewed } \\
\text { academic publications and } \\
\text { presentations in a variety of fields, } \\
\text { including computer science, } \\
\text { rehabilitation science, engineering, }\end{array}$ & $\begin{array}{l}\text { The close collaboration and sense } \\
\text { of teamwork has resulted in the } \\
\text { team wanting to ensure that the } \\
\text { transdisciplinary nature of the } \\
\text { project is conveyed. Examples } \\
\text { include authors explicitly using the } \\
\text { shared vocabulary developed by } \\
\text { the research team and commenting } \\
\text { on the significance of the work } \\
\text { with respect to other fields (e.g., a } \\
\text { paper targeting a computer science } \\
\text { audience would touch on clinical }\end{array}$ \\
\hline
\end{tabular}


PRINCIPLES FOR TRANSDISCIPLINARY DEVELOPMENT

\begin{tabular}{|c|c|c|}
\hline Principle & Aspects of importance to the $C O A C H$ project & $\begin{array}{l}\text { Examples of transdisciplinary } \\
\text { approaches from the } C O A C H \text { project }\end{array}$ \\
\hline & $\begin{array}{l}\text { gerontology, nursing, and speech- } \\
\text { language pathology. }\end{array}$ & $\begin{array}{l}\text { significance and visa-versa for a } \\
\text { rehabilitation science paper) } \\
\text { - Most team members develop an } \\
\text { appreciation for making their } \\
\text { results accessible to a general } \\
\text { audience. } \\
\text { - Efforts have been made to share } \\
\text { COACH project with the general } \\
\text { public through media interviews, } \\
\text { websites, and educational sessions. }\end{array}$ \\
\hline Maximise impact & $\begin{array}{l}\text { - COACH has notably advanced } \\
\text { several fields, and with ongoing } \\
\text { development for almost } 20 \text { years, it is } \\
\text { considered a project that established } \\
\text { the growing field of ambient assisted } \\
\text { living technologies. }\end{array}$ & $\begin{array}{l}\text { - Input into the development and } \\
\text { evaluation of prototypes by } \\
\text { representative users of the } \\
\text { technology (i.e., people with } \\
\text { dementia and caregivers) has } \\
\text { enabled a team from diverse } \\
\text { backgrounds to gain a first-hand } \\
\text { understanding of what works and } \\
\text { what does not, permits more } \\
\text { robust knowledge transfer (both } \\
\text { internally and externally to the } \\
\text { team), and lends legitimacy to the } \\
\text { technology. } \\
\text { - Advances made through the } \\
\text { development of COACH have } \\
\text { benefited later COACH } \\
\text { prototypes, as well as other } \\
\text { projects within the area of ambient } \\
\text { assisted living and beyond. }\end{array}$ \\
\hline
\end{tabular}

\section{Conclusions and future directions}

Demographic changes and the increasing prevalence of chronic disease and neurological impairment is a global concern. Historically assistive technologies have enabled functional performance. Recent advances in assistive technology design have included the incorporation of information and communication technologies as well as pervasive computing. Although this technological progression should be embraced, it widens the complexity of the technologies and 


\section{PRINCIPLES FOR TRANSDISCIPLINARY DEVELOPMENT}

requires the need for new skill sets and perspectives. In particular, a transdisciplinary approach is needed to support the development of assistive technologies that are responsive to the needs of technology users and are commercially viable. The principles presented in this paper are grounded in the literature and the authors' experiences, however, they are in their theoretical conceptual stage; while they have been implemented within individual projects, they have not been validated through scrutinised applications to real-world situations as a working set of principles. This next phase of development of these principles involves their testing and refinement through several projects of the AGE-WELL Network of Centres of Excellence (NCE). AGE-WELL NCE is a pan-Canadian network of industry, non-profit organisations, government, care providers, caregivers, representative technology users, and academic partners working together using high-quality research to drive innovation and create technologies and services that benefit older adults. AGE-WELL's vision is to harness and build upon the potential of emerging and advanced technologies in areas such as artificial intelligence, e-health, information communication technologies, and mobile technologies to stimulate technological, social, and policy innovation. The Network's aim to help older Canadians maintain their independence, health and quality of life through accessible technologies that increase their safety and security, support their independent living, and enhance their social participation.

The principles presented in this paper are not meant to supersede the need for transdisciplinary collaborators to research methods and models that complement the needs of their project or team; rather, they are intended to form a high-level backbone that supports collaborative technology development. In addition to testing, refining, and validating the principles put forward by this paper, future work needs to include the development of actual process of products or services that enable transdisciplinary development of solutions. 


\section{PRINCIPLES FOR TRANSDISCIPLINARY DEVELOPMENT}

\section{$7 \quad$ References}

1. Hocking C. Contribution of occupation to health and well-being. In: Crepeau EB, Cohn ES, Boyt Schell BA, editors. Willard \& Spackman's occupational therapy. 11th ed. Philadelphia, PA: Wolters Kluwer/Lippincott Williams \& Wilkins; 2009.

2. ACTIVE ASSISTED LIVING PROGRAMME. July 20. ACTIVE ASSISTED LIVING

PROGRAMME. <http://www.aal-europe.eu/>. Accessed 2015 July 20.

3. AGE-WELL. July 20. AGE-WELL | Canada's Technology and Aging Network.

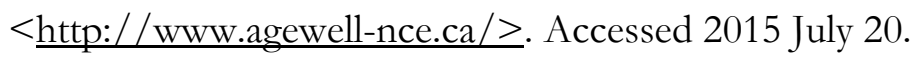

4. Sixsmith A. Technology and the Challenge of Aging. Technologies for Active Aging: Springer; 2013. p 7-25.

5. Jackson P, Sixsmith J, Mihailidis A, Sixsmith A. Perspectives on Collaboration in Technology Innovation for Ageing. Inclusive Smart Cities and e-Health, LNCS: Springer; 2015. p 27-37.

6. Darbellay F. Rethinking inter-and transdisciplinarity: Undisciplined knowledge and the emergence of a new thought style. Futures 2015;65:163-174.

7. Stokols D, Misra S, Moser RP, Hall KL, Taylor BK. The ecology of team science: understanding contextual influences on transdisciplinary collaboration. American journal of preventive medicine 2008;35(2):S96-S115.

8. McGill P. What is interdisciplinary? Considerations for researchers. Belfast, Northern Ireland: Centre for Ageing Research and Development in Ireland (CARDI); 2009. Report nr Occasional Paper.

9. Brown VA. Utopian thinking and the collective mind: Beyond transdisciplinarity. Futures 2015;65(Complete):209-216.

10. Rittel HWJ, Webber MM. Dilemmas in a general theory of planning. Policy Sciences 1973;4(2):155-169.

11. Conklin J. Wicked Problems and Social Complexity. Dialogue Mapping: Building Shared Understanding of Wicked Problems. West Sussex, UK: Wiley; 2005. p 3-40.

12. Gray B. Enhancing Transdisciplinary Research Through Collaborative Leadership. American Journal of Preventive Medicine 2008;35(2):S124-S132.

13. Hadorn GH, Biber-Klemm S, Grossenbacher-Mansuy W, Hoffmann-Riem H, Joye D, Pohl C, Wiesmann U, Zemp E. The Emergence of Transdisciplinarity as a Form of Research. In: 
Hadorn GH, Hoffmann-Riem H, Biber-Klemm S, Grossenbacher-Mansuy W, Joye D, Pohl C, Wiesmann U, Zemp E, editors. Handbook of Transdisciplinary Research. The Netherlands: Springer; 2008. p 19-39.

14. Etzkowitz H. Innovation in Innovation: The Triple Helix of University-IndustryGovernment Relations. Social Science Information 2003;42(3):293-337.

15. Rubin J. Handbook of Usability, How to plan, design and conduct effective tests,. New York, NY: John Wiley \& Sons; 1994.

16. Norman D, Miller J, Henderson A. What You See, Some of What's in the Future, And How We Go About Doing It: HI at Apple Computer. CHI 1995. Denver, CO1995.

17. Beyer H, Holtzblatt K. Contextual Design: Defining Customer-Centered Systems. San Francisco, CA: Morgan Kaufmann; 1998.

18. Lewin K. Action Research and Minority Problems. Journal of Social Issues 1946;2(4):34-46.

19. Bødker S. The AT-project: practical research in cooperative design. DAIMI Report Series $1993 ; 454$.

20. Siew S-T, Yeo AW. Employing participatory action research to augment software development for rural communities. Proceedings of the 25th BCS Conference on HumanComputer Interaction. Newcastle-upon-Tyne, United Kingdom: British Computer Society; 2011. p 171-176.

21. Pohl C, Hadorn GH. Principles for designing transdisciplinary research. oekom Munich; 2007.

22. Cook A, Polgar J. Assistive Technologies: Principles \& Practices. St. Louis, MO: Elsevier/Mosby; 2015.

23. Scherer M. Living in the state of stuck: How technology impacts the lives of persons with disabilities. Brookline Books; 2005.

24. Hester PT, Adams KM. Thinking Systemically About Complex Systems. Procedia Computer Science 2013;20:312-317.

25. Kueffer C, Hadorn GH, Bammer G, van Kerkhoff L, Pohl C. Towards a publication culture in transdisciplinary research. GAIA 2007;16(1):22-26.

26. Klein JT. Discourses of transdisciplinarity: Looking Back to the Future. Futures 2014;63(0):68-74. 


\section{PRINCIPLES FOR TRANSDISCIPLINARY DEVELOPMENT}

27. Stokols D, Hall KL, Taylor BK, Moser RP. The science of team science: overview of the field and introduction to the supplement. American journal of preventive medicine 2008;35(2):S77-S89.

28. Mitchell C, Cordell D, Fam D. Beginning at the end: The outcome spaces framework to guide purposive transdisciplinary research. Futures 2015;65(Complete):86-96.

29. Roux DJ, Stirzaker RJ, Breen CM, Lefroy EC, Cresswell HP. Framework for participative reflection on the accomplishment of transdisciplinary research programs. Environmental Science and Policy 2010;13(8):733-741.

30. Schauppenlehner-Kloyber E, Penker M. Managing group processes in transdisciplinary future studies: How to facilitate social learning and capacity building for self-organised action towards sustainable urban development? Futures 2015;65(Complete):57-71.

31. Klein JT. Evaluation of Interdisciplinary and Transdisciplinary Research: A Literature Review. American Journal of Preventive Medicine 2008;35(2, Supplement):S116-S123.

32. Suchman LA. Plans and situated actions: The problem of human-machine communication. Cambridge: Cambridge University Press; 1987.

33. Dourish P. Where the Action Is: The Foundations of Embodied Interaction. Cambridge, MA: MIT Press; 2001.

34. Aldrich RM. From complexity theory to transactionalism: Moving occupational science forward in theorizing the complexities of behavior. Journal of Occupational Science 2008;15(3):147-156.

35. Scherer M, Jutai J, Fuhrer M, Demers L, Deruyter F. A framework for modelling the selection of assistive technology devices (ATDs). Disability and Rehabilitation: Assistive Technology 2007;2(1):1-8.

36. Story MF. Maximizing Usability: The Principles of Universal Design. Assistive Technology 1998;10(1):4-12.

37. Clarkson JP, Coleman R. History of Inclusive Design in the UK. Applied Ergonomics 2015;46(Part B):235-247.

38. Flagg J, Lane J, Lockett M. Need to Knowledge (NtK) Model: an evidence-based framework for generating technological innovations with socio-economic impacts. Implementation Science 2013;8(1):21.

39. Mankins JC. Technology readiness levels: A White Paper. Advanced Concepts Office, Office of Space Access and Technology, NASA; 1995. 


\section{PRINCIPLES FOR TRANSDISCIPLINARY DEVELOPMENT}

40. Mankins JC. Technology readiness assessments: A retrospective. Acta Astronautica 2009;65(9-10):1216-1223.

41. Carew AL, Wickson F. The TD wheel: a heuristic to shape, support and evaluate transdisciplinary research. Futures 2010;42(10):1146-1155.

42. Rosendahl J, Zanella MA, Rist S, Weigelt J. Scientists' situated knowledge: strong objectivity in transdisciplinarity. Futures 2015;65:17-27.

43. Mihailidis A, Boger J, Hoey J, Jiancaro T. Zero Effort Technologies: Considerations, Challenges and Use in Health, Wellness, and Rehabilitation. In: Baecker RM, editor. Synthesis Lectures on Assistive, Rehabilitative, and Health-Preserving Technologies. San Rafael, CA: Morgan \& Claypool Publishers; 2011.

44. Boger J, Hoey J, Poupart P, Boutilier C, Fernie G, Mihailidis A. A planning system based on Markov decision processes to guide people with dementia through activities of daily living. IEEE Transactions on Information Technology in Biomedicine 2006;10(2):323-333.

45. Czarnuch S, Mihailidis A. Development and evaluation of a hand tracker using depth images captured from an overhead perspective. Disability and Rehabilitation: Assistive Technology 2015; early online:1-8.

46. Hoey J, Poupart P, von Bertoldi A, Craig T, Boutilier C, Mihailidis A. Automated Handwashing Assistance For Persons With Dementia Using Video and A Partially Observable Markov Decision Process. Computer Vision and Image Understanding - Special Issue on Computer Vision Systems 2010;114(5):503-519.

47. Mihailidis A, Boger JN, Craig T, Hoey J. The COACH prompting system to assist older adults with dementia through handwashing: An efficacy study. BMC Geriatrics 2008;8(28).

48. Mihailidis A, Carmichael B, Boger J. The use of computer vision in an intelligent environment to support aging-in-place, safety, and independence in the home. IEEE Transactions on Information Technology in Biomedicine 2004;8(3):238-247.

49. Labelle K-L, Mihailidis A. The Use of Automated Prompting to Facilitate Handwashing in Persons With Dementia. American Journal of Occupational Therapy 2006;60(4):442-450.

50. Mihailidis A, Cockburn A, Longley C, Boger J. The acceptability of home monitoring technology among community-dwelling older adults and baby boomers. Assistive Technology 2008;20(1):1 - 12.

51. Bieńkiewicz MMN, Brandi M-L, Goldenberg G, Hughes C, Hermsdörfer J. The tool in the brain: Apraxia in ADL. Frontiers in Psychology 2014;5(Article 353):1-13. 


\section{PRINCIPLES FOR TRANSDISCIPLINARY DEVELOPMENT}

52. Hoey J, Von Bertoldi A, Poupart P, Mihailidis A. Assisting persons with dementia during handwashing using a partially observable Markov decision process. The 5th International Conference on Computer Vision Systems. Bielefeld, Germany2007.

53. Wilson R, Rochon E, Mihailidis A, Leonard C. Quantitative analysis of formal caregivers' use of communication strategies while assisting individuals with moderate and severe

Alzheimer's disease during oral care. Journal of Communication Disorders 2013;46(3):249263.

54. Boger J, Craig T, Mihailidis A. Examining the impact of familiarity on faucet usability for older adults with dementia. BMC Geriatrics 2013;13(63).

55. Boger J, Hoey J, Fenton K, Craig T, Mihailidis A. Using actors to develop technologies for older adults with dementia: A pilot study. Gerontechnology 2010;9(4):450-463. 